\title{
Autophagy induced by Schwann cell-derived exosomes promotes recovery after spinal cord injury in rats
}

\author{
Dayu Pan · Shibo Zhu $\cdot$ Weixin Zhang $\cdot$ Zhijian Wei $\cdot$ Fuhan Yang • \\ Zhenglong Guo $\cdot$ Guangzhi Ning $\cdot$ Shiqing Feng $(\mathbb{D}$
}

Received: 3 May 2021 / Accepted: 15 October 2021 / Published online: 5 November 2021

(C) The Author(s) 2021

\begin{abstract}
Spinal cord injury (SCI) is catastrophic to humans and society. However, there is currently no effective treatment for SCI. Autophagy is known to serve critical roles in both the physiological and pathological processes of the body, but its facilitatory and/or deleterious effects in SCI are yet to be completely elucidated. This study aimed to use primary Schwann cell-derived exosomes (SCDEs) to treat rats after SCI. In the present study, SCDEs were purified and their efficacy in ameliorating the
\end{abstract}

Dayu Pan, Shibo Zhu and Weixin Zhang: First author: These authors have equal contribution to this research.

Supplementary Information The online version contains supplementary material available at https://doi.org/10.1007/ s10529-021-03198-8.

D. Pan $\cdot$ S. Zhu $\cdot$ Z. Wei $\cdot$ G. Ning $\cdot$ S. Feng

Department of Orthopedics, Tianjin Medical University

General Hospital, Heping District, Tianjin 300052, China

D. Pan $\cdot$ S. Zhu $\cdot$ Z. Wei $\cdot$ G. Ning $\cdot$ S. Feng

International Science and Technology Cooperation Base of Spinal Cord Injury, Tianjin Key Laboratory of Spine and Spinal Cord Injury, Department of Orthopedics,

Tianjin Medical University General Hospital, Tianjin, China

W. Zhang

Zhejiang Chinese Medicine University, 548 Binwen

Road, Hangzhou 310053, China components of SCI was examined. Using both in vivo and in vitro experiments, it was demonstrated that SCDEs increased autophagy and decreased apoptosis after SCI, which promoted axonal protection and the recovery of motor function. Furthermore, it was discovered that an increased number of SCDEs resulted in a decreased expression level of EGFR, which subsequently inhibited the Akt/mTOR signaling pathway, which upregulated the level of autophagy to ultimately induce microtubule acetylation and polymerization. Collectively, the present study identified that SCDEs could induce axonal protection after SCI by increasing autophagy and decreasing apoptosis, and it was suggested that this may involve the EGFR/Akt/mTOR signaling pathway.

F. Yang

Department of Urology, Shanghai Tenth People's

Hospital, Tongji University, Shanghai, China

Z. Guo

Henan Provincial People's Hospital, People's Hospital of Zhengzhou University, People's Hospital of Henan University, Henan, China

G. Ning $(\bowtie) \cdot$ S. Feng $(\square)$

Department of Orthopedic Surgery, Tianjin Medical University General Hospital, Tianjin 300052, China e-mail: ningguangzhi@foxmail.com

S. Feng

e-mail: sqfeng@tmu.edu.cn 
Keywords Schwann cell $\cdot$ Exosome $\cdot$ Spinal cord injury $\cdot$ Autophagy $\cdot$ EGFR/Akt/mTOR signaling pathway

\section{Introduction}

Spinal cord injury (SCI) causes severe damage to axons and results in the death of neurons, which leads to the permanent loss of motor and/or sensory function. Globally, a total of $\sim 2.5$ million individuals suffer from traumatic SCI, with $>130,000$ new cases reported each year in the world (Holmes 2017; McDonald and Sadowsky 2002; Thuret et al. 2006). However, there is currently no effective treatment for SCI (Mothe and Tator 2012).

Exosomes are small endosome-derived vesicles $(30-150 \mathrm{~nm})$ that contain complex RNAs and proteins, but have more recently been referred to as discshaped vesicles having a diameter of $40-100 \mathrm{~nm}$ (Thery et al. 2002). Moreover, exosomes represent extracellular cell-derived phospholipid nanocarriers that act as signaling bodies and can deliver biologically active molecules to specific recipient cells for intercellular communication (Yang et al. 2019). It has been reported that exosomes can cross the blood-brain barrier, can enable multiple intravenous dosing without any side effects and can participate in the regulation of inflammation to promote nerve and motor functional recovery (Lopez-Verrilli et al. 2013). In the peripheral nervous system, Schwann cells promote the dedifferentiation and proliferation of axons after injury, as well as remove myelin and axon fragments. Moreover, their regenerative capacity has been applied to repair damage within the central nervous system (Webber and Zochodne 2010). Therefore, the present study further investigated the potential of Schwann cell-derived exosomes (SCDEs) in the recovery after SCI.

Autophagy is a metabolic process in which a class of intracellular substances is degraded, and autophagosomes have been observed in the nervous system (Chen et al. 2017; He et al. 2016; Yang et al. 2013). Previous studies have reported that crush injury of the optic nerve leads to the rapid entry of calcium into neurons, which subsequently induces autophagy and ultimately leads to axonal degeneration (Koch et al. 2010). Moreover, multiple studies have shown that exosomes are closely associated with autophagy. As such, the purpose of the present study was to investigate the role of SCDEs in axonal protection following SCI, as well as identify its possible mechanisms. The present findings may contribute to the development of novel therapeutic strategies for treating clinical SCI.

\section{Materials and methods}

Animals and injections

Female Wistar rats (weight, $240 \pm 10 \mathrm{~g}$; weight range, 230-250 g; $n=120$ ) were obtained from the Laboratory Animal Center of the Chinese People's Liberation Army General Hospital (Beijing, China). These rats were divided into the following groups ( $n=6$ rats/group): Sham group, without surgery and SCDEs injection; control group, injected with PBS; and SCDEs group, injected with SCDEs. The rats were housed at a temperature of $25 \pm 1{ }^{\circ} \mathrm{C}$ with a $12 \mathrm{~h}$ light/dark cycle, and access to food and water was ad libitum. All animals were handled according to the recommendations of the National Institute of Health Guidelines for the Care and Use of Laboratory Animals. The experiments were approved by the Animal Ethical and Welfare Committee (approval no. IRM-DWLL-2017021). In total, $250 \mu \mathrm{L}$ exosomes $(0.1 \mu \mathrm{g} / \mu \mathrm{L})$ and an equal volume of Dulbecco's Phosphate Buffered Saline (DPBS) were injected into the tail veins of the rats three times a week for 4 weeks since the induction day of SCI.

\section{SCI}

The rats were weighed and deeply anesthetized with an intraperitoneal injection of $400 \mathrm{mg} / \mathrm{kg} 4 \%$ chloral hydrate. After a $1-\mathrm{cm}$ skin incision was made at the T10 position of the back, the muscles of the localized area were bluntly separated to expose the T10 lamina. Subsequently, a dorsal laminectomy of the T10 vertebra was performed to expose the spinal cord. A striking rod was placed directly above the exposed spinal cord, and a 10-g node was freely dropped from a height of $2.5 \mathrm{~cm}$, resulting in a model of spinal cord contusion. Finally, the muscle and skin were sutured layer by layer after all bleeding was stopped. Sodium cefuroxime was used for 3 days after surgery to 
prevent wound infection, and the rats were provided with manual assistance in emptying their bladders twice a day. The humane endpoints included autotomy, pain or distress, weight loss of $>20 \%,>70 \%$ reduction in food intake, lethargy or apathy and severe wound scratching.

\section{Behavioral testing of locomotor function}

The Basso, Beatlie and Bresnahan (BBB) functional score was used to quantify locomotor function (Basso et al. 1995). The test was performed before the spinal cord surgery and weekly thereafter at the same time of day and were graded by the three blinded observers. Functional restoration was assessed as per BBB locomotor scores, as previously described (Basso et al. 1995). The BBB test score evaluated hindlimb locomotor function on a scale from 0 to 21. Scoring was based on spontaneous hindlimb movement during a 5-min observation period in the open field after the animals already habituated to the arena. The animals $(n=6)$ were placed on a circular platform with a diameter of $2 \mathrm{~m}$, and the walking and limb activities of the hind limbs were observed.

\section{Cell culture}

The PC12 cell line was generously provided by Professor Haifang Yin from Research Centre of Basic Medical Science of Tianjin Medical University (Tianjin, China). Cells were cultured in DMEM containing $10 \%$ bovine serum, $5 \%$ horse serum, $1 \%$ L-glutamine and $1 \%$ penicillin/streptomycin. All cells were cultured at $37{ }^{\circ} \mathrm{C}$ with $5 \% \mathrm{CO}_{2}$. For the construction of an oxidative stress model that emulates SCI in vitro, PC12 cells were incubated for $24 \mathrm{~h}$ in fresh medium containing $200 \mu \mathrm{M} \mathrm{H}_{2} \mathrm{O}_{2}$. Then, $3 \mathrm{~mL}$ serum-free medium containing $50 \mu \mathrm{g} / \mathrm{L}$ of nerve growth factor was used to induce the differentiation of PC12 cells for 5 days.

Primary Schwann cells were extracted from the sciatic nerves of adult Wistar rats and cultured in DMEM with $10 \%$ FBS and $1 \%$ penicillin /streptomycin at $37{ }^{\circ} \mathrm{C}$ with $5 \% \mathrm{CO}_{2}$. The medium condition was changed when the cells grew up to $80 \%$ area of the culture dish. For exosomes collection, Schwann cells were cultured in DMEM supplemented with $10 \%$ exosome-free FBS and $1 \%$ penicillin/streptomycin at

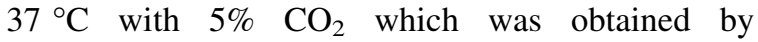

centrifuging FBS at $100,000 \times g$ for $16 \mathrm{~h}$ at $4{ }^{\circ} \mathrm{C}$. The isolated Schwann cells were characterized via costaining of glial fibrillary acidic protein and S100 (Fig. S1A, B).

Preparation and purification of SCDEs

The resulting culture medium of Schwann cells was harvested to obtain exosomes via multiple ultracentrifugation steps. The first centrifugation was conducted at $1000 \times g$ for $10 \mathrm{~min}$, while the second centrifugation was performed at 10,000 $\times g$ (Beckman Optimal-100 XP, Beckman Coulter, Germany) for $30 \mathrm{~min}$. Subsequently, the supernatant was collected for the third time and ultracentrifuged at $100,000 \times g$ for $1 \mathrm{~h}$. After washing the SCDEs with PBS, the SCDEs were obtained after a final ultracentrifugation for $1 \mathrm{~h}$ at $100,000 \times g$ and been resuspended in sterile PBS for the following experiments. The total protein concentration of exosomes was quantified using a Bradford assay (Sangon Biotech Co., Ltd.).

\section{Characterization of SCDEs}

The size distribution of exosomes was measured using a nanoparticle tracking and zeta potential distribution analyzer (Paricle Metrix-PMX, Germany) and the morphology of the exosomes was visualized using a high-resolution transmission electron microscope (TEM, Hitachi HT7700, Tokyo, Japan). Briefly, the re-suspended exosomes were mixed with an equal volume of $4 \%$ paraformaldehyde (PFA) and adsorbed onto a glow-discharged, carbon-coated formvar film, which was attached to a metal specimen grid. Excess solution was blotted off and the grid was immersed with a small drop $(50 \mu \mathrm{L})$ of $1 \%$ glutaraldehyde for 5 min followed by washing with $100 \mu \mathrm{L}$ still water 2 min each time for 8 times. Subsequently, the grid was transferred to $50 \mu \mathrm{L}$ uranyl-oxalate solution (pH 7.0) for $5 \mathrm{~min}$ and then $50 \mu \mathrm{L}$ methyl cellulose-uranyl acetate $(100 \mu \mathrm{L} 4 \%$ uranyl acetate and $900 \mu \mathrm{L} 2 \%$ methyl cellulose) for $10 \mathrm{~min}$ on ice. The excess solution was blotted off and the sample was dried and examined in the TEM.

Protein extraction and western blotting

SCDEs and cell pellets were lysed with RIPA buffer, and the protein sample was then boiled and denatured 


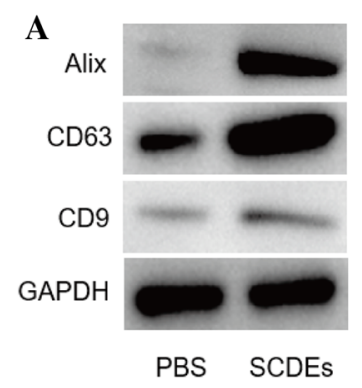

B

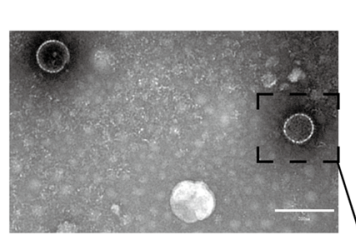

Sham
C
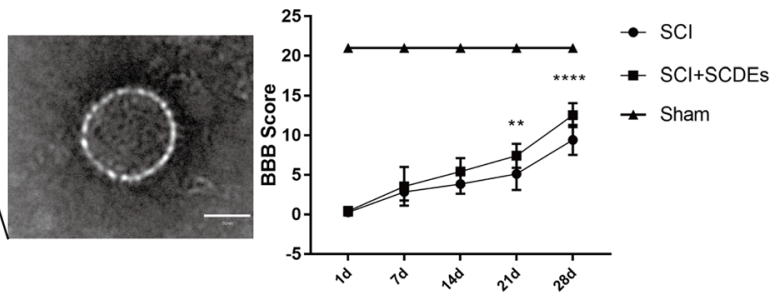

$\mathrm{SCl}$

SCI+SCDES

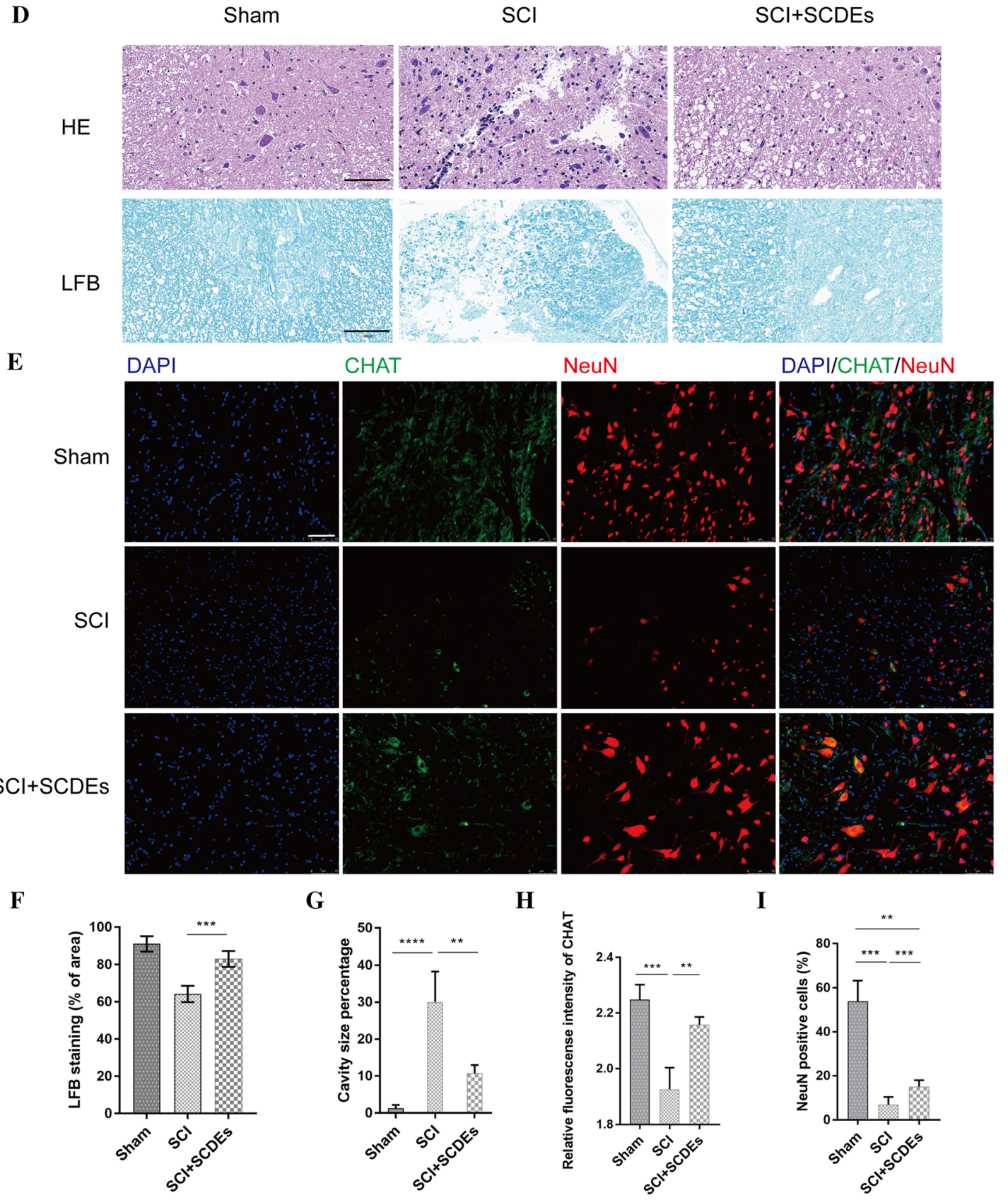


4Fig. 1 Characterizations of SCDEs, which can improve spinal cord repair after SCI in vivo. A Western blot analysis of the expression levels of CD9, CD63 and Alix in exosomes extracted from Schwann cells. B Image of exosomes under transmission electron microscopy. Scale bars denote the following: Left side, $200 \mu \mathrm{m}$; right side, $50 \mu \mathrm{m}$. C BBB scores are indicative of locomotor function after SCI in rats. Data are presented as the mean \pm SEM; two-way ANOVA with Tukey's post-hoc test, $\mathrm{n}=6 . * \mathrm{P}<0.05, * * \mathrm{P}<0.01$. D H\&E and luxol fast blue staining of spinal cord sections at 4 weeks after surgery. Scale bar, $100 \mu \mathrm{m}$. E These cells were stained with NeuN, ChAT and DAPI. Scale bar, $75 \mu \mathrm{m}$. F, G Quantification of LFB staining (\% of area) and cavity size percentage. H, I Quantification of the NeuN and ChAT area. Data are presented as the mean \pm SEM, one-way ANOVA followed by a Bonferroni correction, $\mathrm{n}=5$. $* * \mathrm{P}<0.01$, *** $\mathrm{P}<0.001$, **** $\mathrm{P}<0.0001$. SCDEs Schwann cell-derived exosomes, $S C I$ spinal cord injury, Alix ALG-2 interacting protein $\mathrm{X}, C h A T$ choline acetyltransferase, $B B B$ Basso, Beatlie and Bresnahan, NeuN neuronal nuclei

in $5 \times$ SDS loading buffer for $15 \mathrm{~min}$. Then, $30 \mu \mathrm{g}$ total protein was loaded per well. Electrophoresis was performed using a $10 \%$ acrylamide gel, and proteins were transferred to a PVDF membrane on ice for $1 \mathrm{~h}$. The membrane was blocked with 5\% BSA at room temperature for $1 \mathrm{~h}$ after transfer. Subsequently, the primary antibody was incubated with the membrane overnight at $4{ }^{\circ} \mathrm{C}$ (Table SI). CD9, CD31 and Alix were picked to indicate the exosome presence (Thery et al., 2018). The following day the membrane was incubated with secondary antibody (1:2000) for $1 \mathrm{~h}$ at room temperature. Finally, the ECL immunoblot analysis system (EMD Millipore) was applied to visualize the bands.

\section{Immunofluorescent staining}

In total, five rats per group and the 20th-25th slices were used for immunofluorescent staining. After anesthetizing the rats with $400 \mathrm{mg} / \mathrm{kg} 4 \%$ chloral hydrate and exposing the heart, a small hole was cut in the left ventricle and a needle was inserted into the aorta, then the right atrium was cut to allow flow. Perfusion with $200 \mathrm{~mL}$ cold saline was followed by fixing with $300 \mathrm{~mL}$ cold $4 \%$ paraformaldehyde at weeks 1, 2 and 4 post-SCI. The removed spinal cord tissue was $1-\mathrm{cm}$ above and below the center of the lesion. Subsequently, the fixed spinal cord was dehydrated overnight in $30 \%$ sucrose, embedded and sliced into frozen sections. Frozen sections (thickness, $10 \mu \mathrm{m}$ ) were blocked with 5\% donkey serum at room temperature for $1 \mathrm{~h}$. Then, sections were incubated with the corresponding primary antibodies at $4{ }^{\circ} \mathrm{C}$ overnight (Table SI), followed by incubation with the corresponding secondary antibodies (conjugated to Alexa Fluor 488 or 594; Invitrogen; Thermo Fisher Scientific, Inc.) for $1 \mathrm{~h}$ at room temperature. Finally, the sections were observed under a LEICA fluorescent microscope.

\section{H\&E staining}

$\mathrm{H} \& \mathrm{E}$ staining was used to assess contusion areas and demyelination in different groups. After the rats were perfused, the spinal cord was removed at $1-\mathrm{cm}$ above and below the center of the lesion and was fixed with $4 \%$ paraformaldehyde overnight, after which it was immersed in PBS. Finally, the spinal cord sample was embedded in paraffin and cut into 5- $\mu$ m thick sections for $H \& E$ staining. In total, five rats per group and the 20th-25th slices were used for H\&E staining.

\section{Luxol fast blue (LFB) staining}

LFB staining was used to stain myelin and myelinated axons. In total, five rats per group and the 20th-25th slices were used for LFB staining. The sections were added into a $0.1 \%$ LFB solution and incubated in an oven at $65{ }^{\circ} \mathrm{C}$ overnight. The following day, the sections were separated with a $0.05 \%$ aqueous lithium carbonate solution for $30 \mathrm{~s}$. Subsequently, the sections were counterstained with a $0.25 \%$ tar-purple solution and a few drops of glacial acetic-acid dye solution for $10 \mathrm{~min}$.

\section{TUNEL staining}

Sections in the center of the injury site were treated according to the manufacturer's instructions of the DeadEnd $^{\mathrm{TM}}$ Fluorometric TUNEL system (cat. no. G3250; Promega Corporation). Quantification was performed by counting the number of TUNEL-positive cells in the whole injury site on five serial sections for each rat, which was performed in duplicate.

\section{Flow cytometry}

The cells were incubated with $5 \mu \mathrm{L}$ of Annexin $\mathrm{V}$ and $5 \mu \mathrm{L}$ of propidium iodide (PI) for $15 \mathrm{~min}$ at room temperature in dark, according to the manufacturer's 
instruction (BD Biosciences, SanJose, CA), and then subjected to flow cytometry to measure the apoptosis rate $(\%)$. Primary PC12 cells $\left(1 \times 10^{6}\right)$ at passage 30 were suspended in DPBS and incubated with antibodies at a dilution of $1: 500$ for $1 \mathrm{~h}$ at $4{ }^{\circ} \mathrm{C}$; isotypematched antibodies served as negative controls. In total, three specimens were tested. Fluorescent compensation was performed using labelled controls and all measures were performed using Flow-Jo (v.7.6; Tree Star, Inc.).

\section{Statistical analysis}

H\&E staining and LFB staining images were converted to black and white, and the area of cavitation was measured in different tissue compartments using ImageJ (v.1.51; National Institutes of Health) software. Fluorescence intensities are expressed as arbitrary units-standard errors of the mean. The cavity size for each slide was recorded using ImageJ software, and eventually, the mean cavity size for each group was measured. The cavity size was presented as percent of the total area of the section using the following formula: Cavity size $(\%)=[$ Cavity size $(\mu \mathrm{m}) /$ Total area of the section $(\mu \mathrm{m})] \times 100$.

All data are presented as the mean \pm SEM. $\mathrm{P}<0.05$ was considered to indicate a statistically significant difference. Statistical analysis was performed using GraphPad Prism 5 software (GraphPad Software, Inc.) and pairwise comparisons were performed using Student's $t$ tests. Two-way ANOVAs with Tukey's post-hoc tests were used to determine significant differences in behaviors that included repeated measures.

\section{Results}

\section{Characterizations of SCDEs}

Western blotting was used to characterize the exosomes, which were found to express three exosomal markers: CD9, CD63 and ALG-2 interacting protein X (Fig. 1A). Furthermore, the size of SCDEs ranged from 40 to $100 \mathrm{~nm}$, as determined via TEM, which provided additional evidence confirming that SCDEs had been isolated (Fig. 1B).
SCDEs improve recovery of motor function after SCI in vivo

For the in vivo experiments, the recovery of rats was assessed after SCI in rats that were treated with or without SCDEs at 1, 7, 14, 21 and 28 days. There were statistically significant differences between the BBB scores of SCDEs-treated rats and sham-treated rats from day 21 (Fig. 1C), such that the BBB scores of SCDEs-treated SCI rats were comparatively improved $(\mathrm{P}<0.05 ; \mathrm{n}=6)$. This finding demonstrates that SCDEs improved recovery of motor function following SCI.

SCDEs improve spinal cord repair after SCI in vivo

Studies have reported that promoting axonal remyelination is an important part of improving spinal nerve function following SCI. H\&E and LFB staining used for the evaluation of myelin content within the spinal cord revealed a noticeable rise in the percentage of myelinated areas and a significant decrease in the area of cavitation after SCDE administration in SCI rats, compared with these parameters in sham-treated SCI rats (Fig. 1D, F, G).

To investigate whether SCDEs affect the protection of injured neurological function, the expression levels of both the mature neural marker, neuronal nuclei $(\mathrm{NeuN})$, and choline acetyltransferase (ChAT), which synthesizes the neurotransmitter acetylcholine in spinal motor neurons, were measured at the injury site in rats. Immunofluorescent results identified that rats treated with SCDEs expressed higher levels of both NeuN and ChAT at the injury site compared with those in the PBS-treated group, suggesting that SCDEs promoted the protection of injured axons (Fig. 1E, H, I).

SCDE treatment after SCI inhibits apoptosis and increases autophagy in vivo

Next, apoptosis was measured via TUNEL assays. There was a significant increase in the number of apoptotic cells in the SCI group compared with that in the sham group $(\mathrm{P}<0.0001)$, while there was a significant decrease in the number of apoptotic cells in the SCDEs-treated SCI group compared with that in the untreated SCI group $(\mathrm{P}<0.01)$. These results 
A

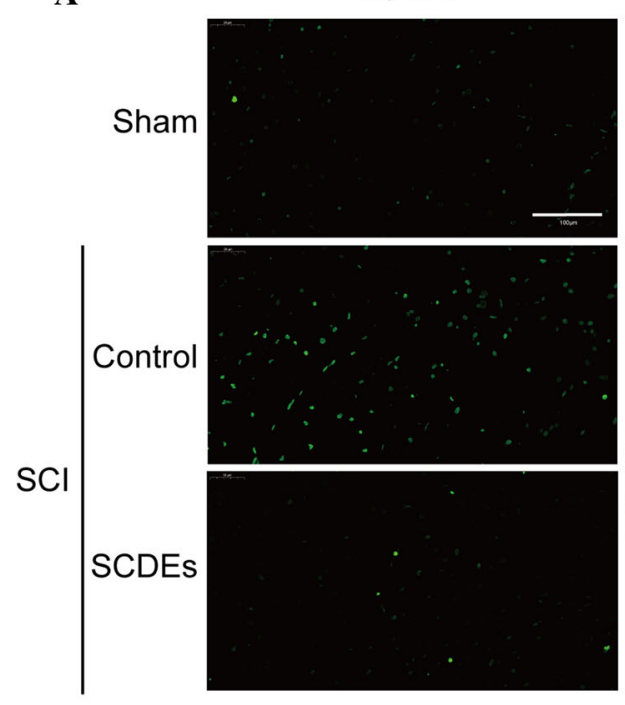

B

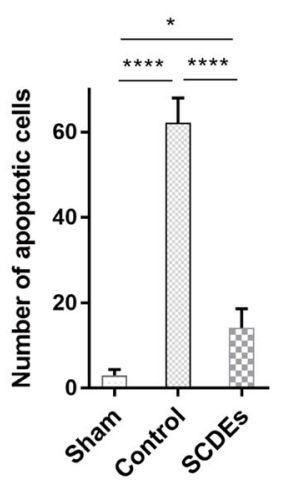

DAPI
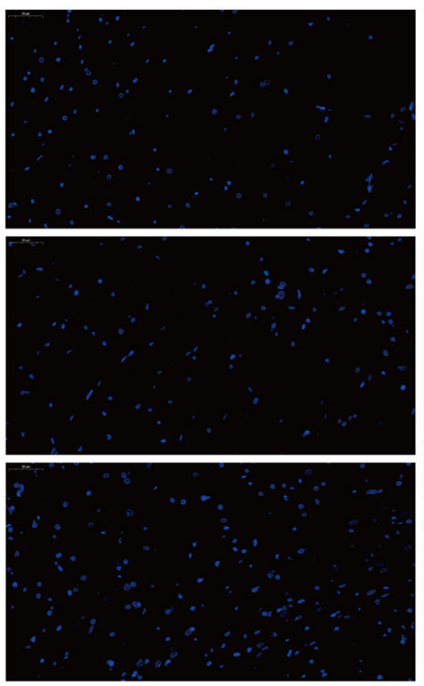

$\begin{array}{ccccc} & \mathrm{H}_{2} \mathrm{O}_{2} & + & + & + \\ \text { Control } & \text { SCDEs+Chlo } & \text { SCDEs }\end{array}$

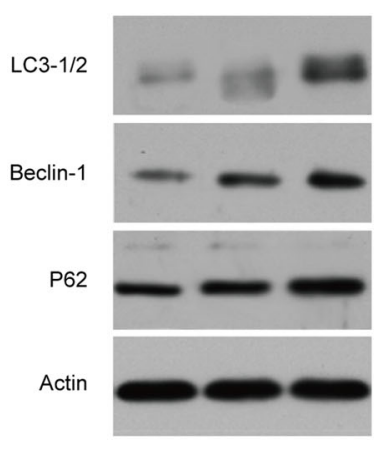

In vivo
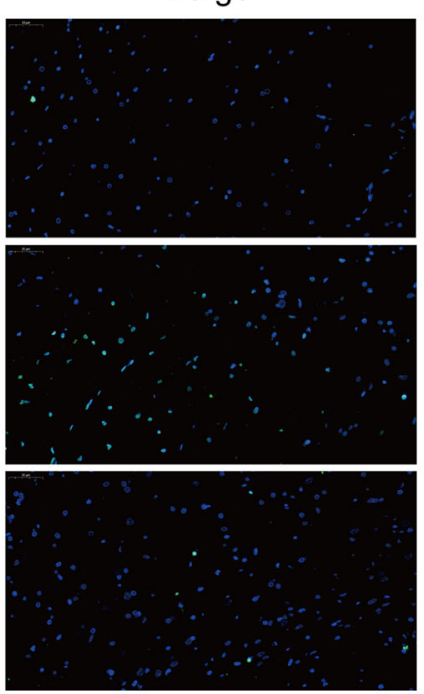

D

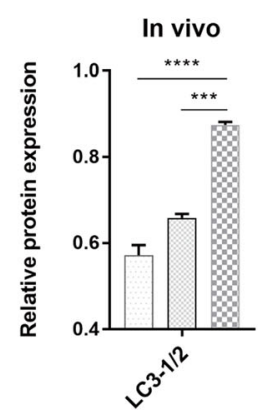

E

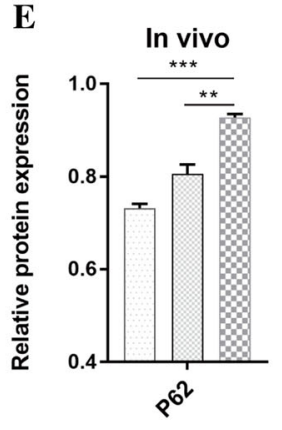

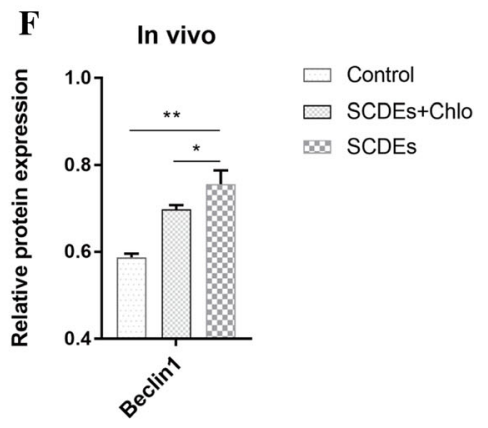

Fig. 2 SCDEs inhibit apoptosis of injured neurons via autophagy in vivo. A These cells were stained with TUNEL in vivo. Scale bar, $100 \mu \mathrm{m}$. B Quantification of the number of apoptotic cells in different groups. C Western blotting results indicated that the SCDE-treatment group expressed higher protein levels of autophagic markers in vivo compared with those of other groups. D-F Quantification of LC3-1/2, Beclin-1 and P62 expression levels Data are presented as the mean \pm SEM, two-way ANOVA with Tukey's post-hoc test, $\mathrm{n}=4$. $* \mathrm{P}<0.05, * * \mathrm{P}<0.01, * * * \mathrm{P}<0.001, * * * * \mathrm{P}<0.0001$. Chlo chloroquine, SCDEs Schwann cell-derived exosomes 
A

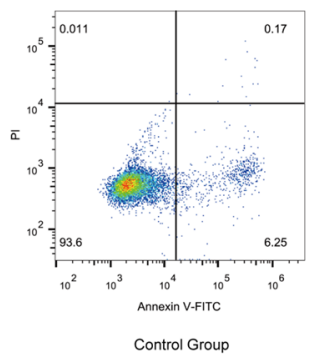

D

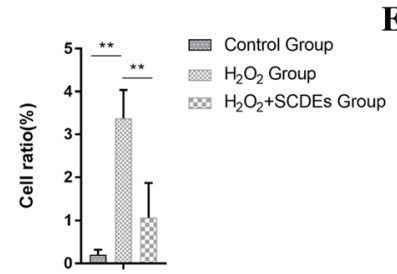

Late apoptosis +Death(\%)
B

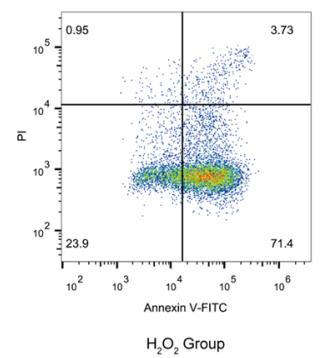

E

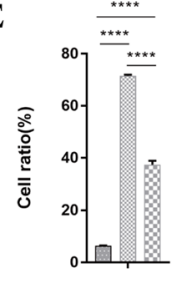

Early apoptosis(\%)
C

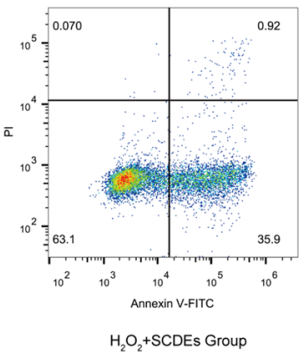

F

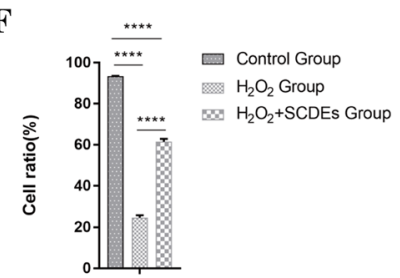

Live cells(\%)

G $\quad \mathrm{H}_{2} \mathrm{O}_{2}$

$+$

$\mathrm{SCl}$
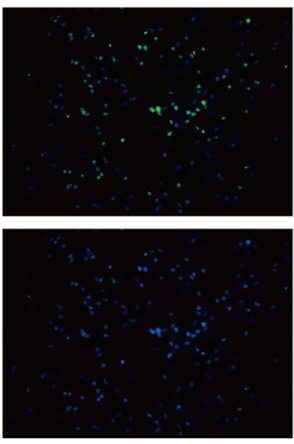

J

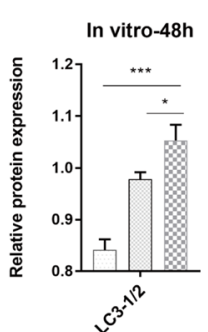

$\square$ Contro

5 SCDES

LC3-1/2

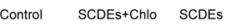

Beclin-1

P62

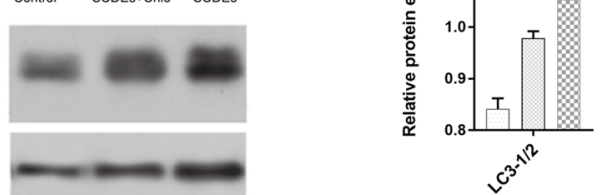

L

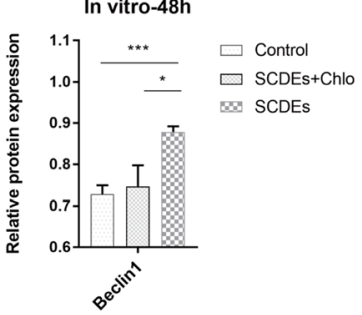

$\square$ SCDEs+Chlo

H

SCI+SCDES

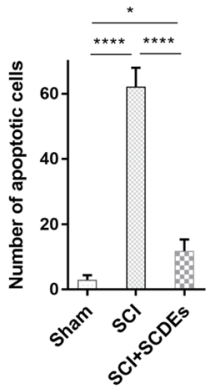

K
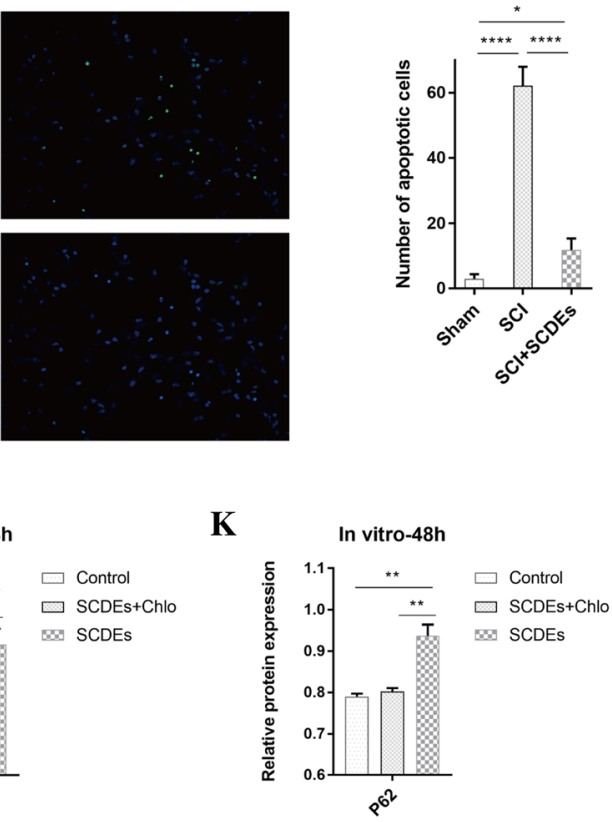

In vitro-48h 
4Fig. 3 SCDEs inhibit apoptosis of injured neurons via autophagy in vitro. A-C Flow cytometry results demonstrated that $\mathrm{H}_{2} \mathrm{O}_{2}$-induced injury increased apoptosis in PC12 cells, which was reduced by SCDE treatment. Cells were classified as healthy cells (Annexin V-, PI -), early apoptotic cells (Annexin $\mathrm{V}+, \mathrm{PI}-$ ), late apoptotic cells (Annexin $\mathrm{V}+$, PI +), and damaged cells (Annexin V - , PI +). D-F Quantification of late apoptosis, death, early apoptosis and live cells. G TUNEL staining identified that apoptosis was notably increased after $\mathrm{H}_{2} \mathrm{O}_{2}$-induced injury, whereas apoptosis was significantly decreased via SCDE treatment. H Quantification of the number of apoptotic cells. I Western blotting indicated that the SCDE-treatment group expressed higher protein levels of autophagic markers compared with those in other groups. JL Semi-quantification of LC3-1/2, Beclin-1 and P62 expression. Scale bar, $100 \mu \mathrm{m}$. Data are presented as the mean \pm SEM, two-way ANOVA with Tukey's post-hoc test, $\mathrm{n}=4$. $* \mathrm{P}<0.05$, $* * \mathrm{P}<0.01, * * * \mathrm{P}<0.001, * * * * \mathrm{P}<0.0001$. SCDEs Schwann cell-derived exosomes

suggested that SCDEs minimized apoptosis following SCI in rats (Fig. 2A and B).

Western blotting was used to detect the expression levels of LC3-1/2, Beclin-1 and P62, which are protein biomarkers of autophagosomes in the damaged spinal cord. The results demonstrated that the damaged spinal cord expressed higher levels of LC3-1/2, Beclin-1 and P62 in the SCDEs-treatment SCI group compared with those in the non-treated SCI group. Additionally, SCDEs-induced increases in LC3-1/2, Beclin-1 and P62 were prevented when autophagy was blocked using chloroquine (Fig. 2C-F). Therefore, these findings indicated that SCDEs may act on injured axons via autophagy.

SCDEs inhibit apoptosis of injured neurons via autophagy in vitro

Next, $\mathrm{H}_{2} \mathrm{O}_{2}$-induced injury in $\mathrm{PC} 12$ cell-induced neurons was used to simulate SCI in vitro. The results of flow cytometry, used for assessing apoptosis, identified that $\mathrm{H}_{2} \mathrm{O}_{2}$-induced injury increased apoptosis in PC12 cell-induced neurons, which was reduced by SCDEs treatment (Fig. 3A-F). Furthermore, to confirm whether SCDEs regulated $\mathrm{H}_{2} \mathrm{O}_{2}$-induced injury in PC12 cell-induced neurons via autophagy, chloroquine was used to block autophagy. Chloroquine is frequently used clinically as an antimalarial agent, is a classic inhibitor of autophagy that blocks the binding of autophagosomes to lysosomes by altering the acidic environment of lysosomes, resulting in the accumulation of a large number of degraded proteins in cells (Golomb 1976; Mushtaque and Shahjahan 2015). TUNEL staining revealed increased neuronal survival in the SCDE treatment group (Fig. 3G and $\mathrm{H}$ ). Western blotting results demonstrated that SCDEs increased the expression levels of LC3-1/2, Beclin-1 and P62 in PC12 cellinduced neurons subjected to $\mathrm{H}_{2} \mathrm{O}_{2}$-induced injury, whereas these SCDE-induced increases were decreased in the presence of chloroquine (Fig. 3I-L). These findings suggest that SCDEs inhibit the apoptosis of injured neurons via autophagy in vitro.

SCDEs inhibit the activation of the Akt/mTOR signaling pathway via the downregulation of EGFR

The western blotting results indicated that when $\mathrm{H}_{2} \mathrm{O}_{2}$ induced injury occurred, EGFR expression was downregulated after SCDEs treatment $(\mathrm{P}<0.01$; Fig. 4A and $\mathrm{B})$. The Akt/mTOR signaling pathway, which was widely been considered to regulate autophagy(HerasSandoval et al., 2014; Zhang et al., 2020), localizes at the downstream target EGFR, and serves an essential role in regulating autophagic progression 34 (Dobashi et al. 2009; Fan et al. 2009; Li et al. 2016b; Ronellenfitsch et al. 2018; Treda et al. 2016). Therefore, western blotting was used to measure the phosphorylation levels of phosphorylated (p)-Akt and p-mTOR, both of which participate in autophagic regulation. Notably, SCDEs treatment decreased these phosphorylation levels in PC12 cell-induced neurons subjected to $\mathrm{H}_{2} \mathrm{O}_{2}$-induced injury (Fig. 4C-F). Collectively, the results suggested that SCDEs-induced autophagy in injured PC12 cell-induced neurons was associated with inhibition of the EGFR/Akt/mTOR signaling axis.

\section{Discussion}

International Society for Extracellular Vesicles (ISEV) endorses "extracellular vesicle" (EV) as the generic term for particles naturally released from the cell that are delimited by a lipid bilayer and cannot replicate, i.e. do not contain a functional nucleus (Thery et al. 2018). SCI can instantly alter and compromise the function of multiple organs of the body, and often leads to irreversible damage and loss 
A

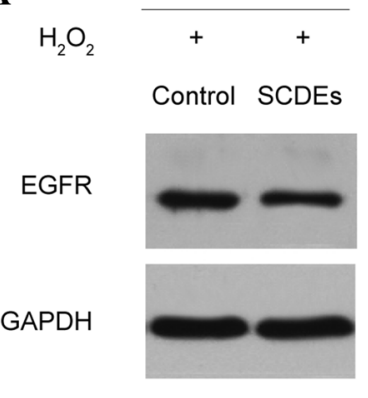

D

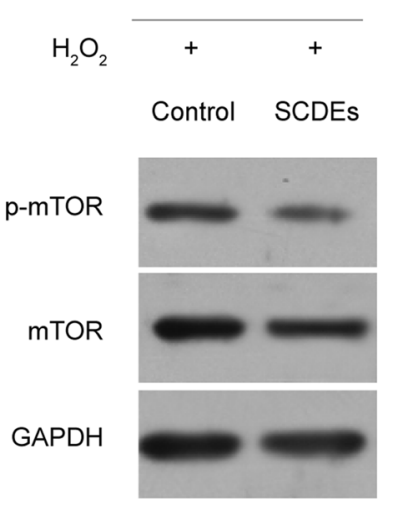

B

$\mathbf{E}$

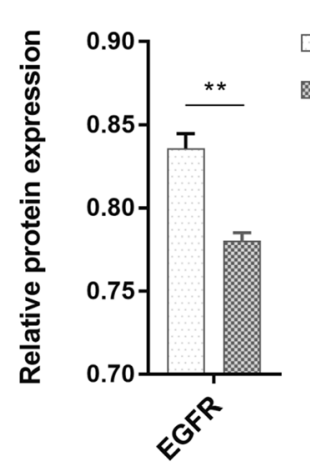

C
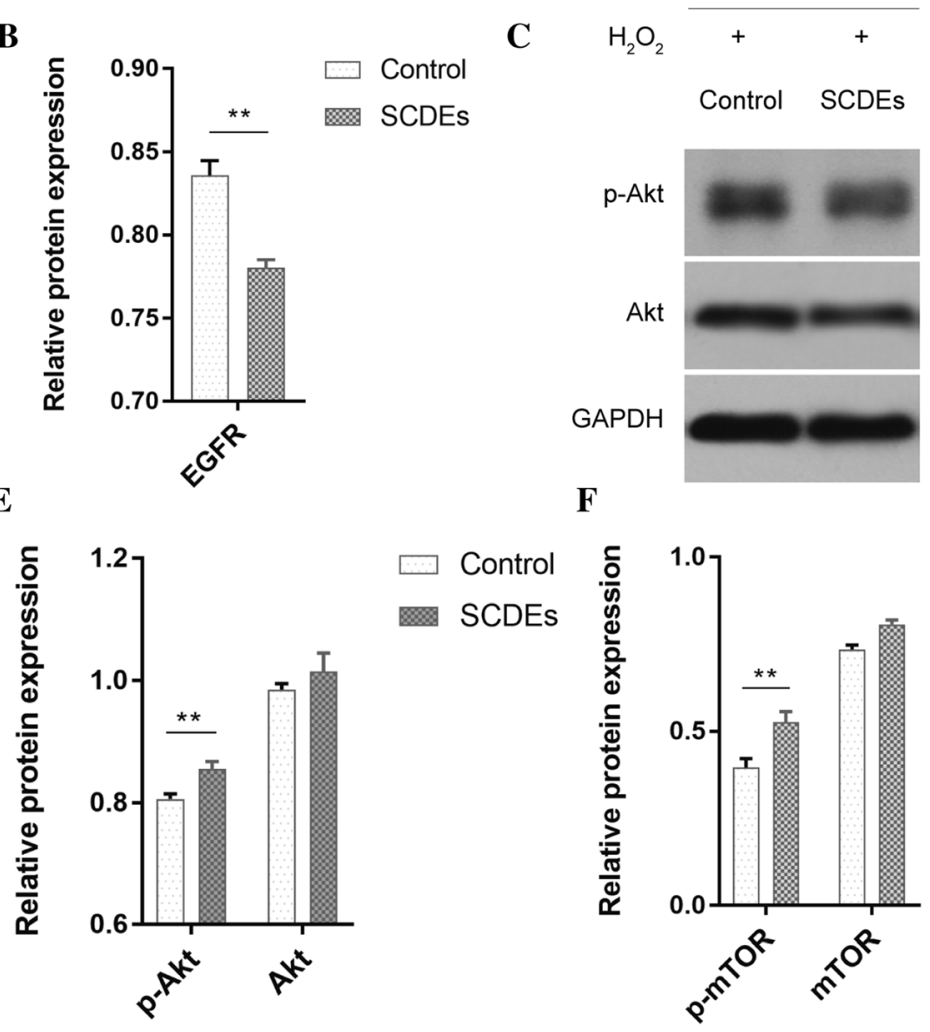

Control

SCDES

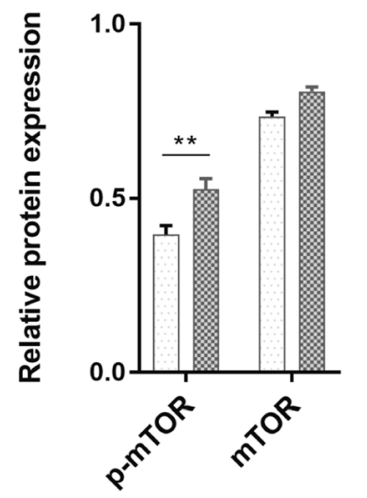

Control SCDES

Fig. 4 SCDEs inhibit the Akt/mTOR signaling pathway by downregulating EGFR. A Western blotting indicated that when $\mathrm{H}_{2} \mathrm{O}_{2}$-induced injury occurred, EGFR was downregulated after SCDE treatment. B Semi-quantification of EGFR expression. C, D The phosphorylation levels of $\mathrm{p}$-Akt and p-mTOR were both notably decreased by SCDE treatment following $\mathrm{H}_{2} \mathrm{O}_{2}$-induced

of sensory, motor and autonomic functions. The cost of care and the social burden associated with SCI are significant, as are the personal costs and injuries to the affected individuals (Ramer et al. 2014).

There are multiple treatments available for SCI, including surgical decompression, methylprednisolone, neuroprotection, magnesium, therapeutic hypothermia and cerebrospinal fluid drainage, as well as the most promising cell-based methods and bioengineering materials. However, the current efficacies of SCI treatments remain limited (Ahuja et al. 2017; de Rivero Vaccari et al. 2016).

The interaction between exosomes and recipient cells has been reported to enable exosomes to bind to cells via conventional receptor-ligand interactions, similar to those of cell-cell communication, membrane/fusion and endocytosis (Cordonnier et al. 2017;

injury. E, F Semi-quantification of p-Akt, Akt, p-mTOR and mTOR expression. Data are presented as the mean \pm SEM, two-way ANOVA with Tukey's post-hoc test, $\mathrm{n}=4$. $* * \mathrm{P}<0.01$. SCDES Schwann cell-derived exosomes, $p$ phosphorylated

Simpson et al. 2008; Sun et al. 2018). It has been shown that exosomes carry biologically active cytokines, such as IL-1 $\beta$, as well as an inflammasome component in the process of activating immune responses, such as via NLR family pyrin domain containing 3-induced inflammation (Qu et al. 2007). Additionally, exosomes regulate Toll-like receptor signaling and IL-1 $\beta$ production (Haneklaus et al. 2013). In promoting axonal regeneration after SCI, exosomes reduce PTEN activity by activating retinoic acid receptor $\beta$ signaling, thereby reducing negative factors that inhibit axonal regeneration and promoting recovery after SCI (Goncalves et al. 2015).

Schwann cells are important components of axons in the peripheral nervous system. Studies have shown that Schwann cells secrete exosomes (Lopez-Verrilli and Court 2012), which promotes axonal regeneration 
both in vitro and in vivo (Ching et al. 2018). However, to the best of our knowledge, the influence of SCDEs on neurons has not been previously investigated. The present study demonstrated that SCDEs promoted the regeneration of axons, the recovery of motor function and the reduction of neuronal apoptosis following SCI.

Autophagy is one of the main pathways for cytosolic degradation and efficient conversion under stress (10). Autophagy involves three steps: Autophagosomal formation, autophagosomal and lysosomal fusion, and autophagic lysosomal degradation (Zhou et al., 2017). The most common mechanisms for upregulating the autophagic flux after traumatic brain injury include the following: increased levels of Beclin 1 protein and a decrease in the Beclin1/BCL2 complex (Diskin et al. 2005; Kanno et al. 2011; Viscomi et al. 2012); enhanced type-III PI3 kinase activity; and autophagic processes. Additionally, it has been revealed that Beclin-1 proteins form a complex with $N$-methyl-D-aspartate receptor 2B (NR2B), which causes the dissociation of the Beclin1/NR2B complex and the release of Beclin-1, which may contribute to induction of autophagy. Another potential mechanism may involve the gap junction protein, connexin 43 , which directly interacts with the Beclin-1 complex and regulates autophagosomal biosynthesis, with some of the proposed pathways including mTOR, GSK3 $\beta$ and BCL2 interacting protein 3 (Bigford et al. 2009; Lin et al. 2014; Yu et al. 2013). The $\mathrm{PI} 3 \mathrm{~K} / \mathrm{AKT} / \mathrm{mTOR}$ pathway is claimed to regulate autophagy to induce apoptosis of alveolar epithelial cells in chronic obstructive pulmonary disease (Zhang et al. 2020) and modulate the clearance of protein to aggregate the neurodegeneration (Heras-Sandoval et al. 2014). Moreover, the PI3K pathway plays several crucial roles in neurogenesis by activating the proliferation, migration, and differentiation of neural stem cells (NSCs) (Koh and Lo 2015). And mTOR plays an important role in the regeneration of neurons, muscles, the liver, and the intestine, which are mainly mediated by $\mathrm{mTORC} 1$ rather than mTORC2 signaling (Wei et al. 2019). Previous studies have reported a close relationship between the different autophagy pathways and the biogenesis and secretion of exosomes. For example, one study revealed that the exosomal microRNA-7-5p mediated bystander autophagy by regulating the EGFR signaling pathway (Baixauli et al. 2014; Cordonnier et al. 2017; Li et al. 2016a; Song et al. 2016).
There were some limitations to the present study. For example, the present study did not upregulate or downregulate the expression levels of EGFR to verify the mechanism via which SCDEs repair SCI through this pathway. The current study also did not elucidate what specific constituents in SCDEs were involved in the regulation of EGFR and the inhibition of downstream pathways to putatively ameliorate SCI.

In conclusion, the present study is the first study to identify that SCDEs could induce axonal protection after SCI by increasing autophagy and decreasing apoptosis, and it was suggested that this may involve the EGFR/Akt/mTOR signaling pathway.

Acknowledgements Not applicable.

Author contributions DP, GN and SF conceived the idea of the study. DP, SZ and WZ carried out the experiment. ZW and FY verified the analytical methods. The authenticity of the raw data have been assessed by DP and SZ. DP wrote the manuscript with support from ZG. All authors discussed the results and contributed to the final manuscript. All authors read and approved the final manuscript.

Funding This work was supported by the National Natural Science Foundation of China (Grant Nos. 81772342 and 82072439), the Key Program of Natural Science Foundation of Tianjin (Grant No. 19JCZDJC36300) and the International Cooperation Program of National Natural Science Foundation of China (Grant No. 81620108018).

Data availability The datasets used and/or analyzed during the present study are available from the corresponding author on reasonable request.

\section{Declarations}

Conflict of interest The authors declare that there is no conflict of interest.

Ethical approval and consent to participate The experiments were approved by the Animal Ethical and Welfare Committee (approval No. IRM-DWLL-2017021).

\section{Patient consent for publication Not applicable.}

Open Access This article is licensed under a Creative Commons Attribution 4.0 International License, which permits use, sharing, adaptation, distribution and reproduction in any medium or format, as long as you give appropriate credit to the original author(s) and the source, provide a link to the Creative Commons licence, and indicate if changes were made. The images or other third party material in this article are included in the article's Creative Commons licence, unless indicated otherwise in a credit line to the material. If material is not included in the article's Creative Commons licence and your intended use is not permitted by statutory regulation or exceeds 
the permitted use, you will need to obtain permission directly from the copyright holder. To view a copy of this licence, visit http://creativecommons.org/licenses/by/4.0/.

\section{References}

Ahuja CS, Nori S, Tetreault L, Wilson J, Kwon B, Harrop J, Choi D, Fehlings MG (2017) Traumatic spinal cord injuryrepair and regeneration. Neurosurgery 80:S9-S22

Baixauli F, Lopez-Otin C, Mittelbrunn M (2014) Exosomes and autophagy: coordinated mechanisms for the maintenance of cellular fitness. Front Immunol 5:403

Basso DM, Beattie MS, Bresnahan JC (1995) A sensitive and reliable locomotor rating scale for open field testing in rats. J Neurotrauma 12:1-21

Bigford GE, Alonso OF, Dietrich D, Keane RW (2009) A novel protein complex in membrane rafts linking the NR2B glutamate receptor and autophagy is disrupted following traumatic brain injury. J Neurotrauma 26:703-720

Chen J, Wang Z, Mao Y, Zheng Z, Chen Y, Khor S, Shi K, He Z, Li J, Gong F, Liu Y, Hu A, Xiao J, Wang X (2017) Liraglutide activates autophagy via GLP-1R to improve functional recovery after spinal cord injury. Oncotarget 8:85949-85968

Ching RC, Wiberg M, Kingham PJ (2018) Schwann cell-like differentiated adipose stem cells promote neurite outgrowth via secreted exosomes and RNA transfer. Stem Cell Res Ther 9:266

Cordonnier M, Chanteloup G, Isambert N, Seigneuric R, Fumoleau P, Garrido C, Gobbo J (2017) Exosomes in cancer theranostic: diamonds in the rough. Cell Adhes Migr 11:151-163

de Rivero Vaccari JP, Brand F 3rd, Adamczak S, Lee SW, Perez-Barcena J, Wang MY, Bullock MR, Dietrich WD, Keane RW (2016) Exosome-mediated inflammasome signaling after central nervous system injury. J Neurochem 136(Suppl 1):39-48

Diskin T, Tal-Or P, Erlich S, Mizrachy L, Alexandrovich A, Shohami E, Pinkas-Kramarski R (2005) Closed head injury induces upregulation of Beclin 1 at the cortical site of injury. J Neurotrauma 22:750-762

Dobashi Y, Suzuki S, Sato E, Hamada Y, Yanagawa T, Ooi A (2009) EGFR-dependent and independent activation of Akt $/ \mathrm{mTOR}$ cascade in bone and soft tissue tumors. Mod Pathol 22:1328-1340

Fan QW, Cheng C, Knight ZA, Haas-Kogan D, Stokoe D, James CD, McCormick F, Shokat KM, Weiss WA (2009) EGFR signals to mTOR through PKC and independently of Akt in glioma. Sci Signal 2:4

Golomb IM (1976) Editorial: the children. N Y J Dent 46:5

Goncalves MB, Malmqvist T, Clarke E, Hubens CJ, Grist J, Hobbs C, Trigo D, Risling M, Angeria M, Damberg P, Carlstedt TP, Corcoran JP (2015) Neuronal RARbeta signaling modulates PTEN activity directly in neurons and via exosome transfer in astrocytes to prevent glial scar formation and induce spinal cord regeneration. J Neurosci 35:15731-15745
Haneklaus M, O’Neill LA, Coll RC (2013) Modulatory mechanisms controlling the NLRP3 inflammasome in inflammation: recent developments. Curr Opin Immunol 25:40-45

He M, Ding Y, Chu C, Tang J, Xiao Q, Luo ZG (2016) Autophagy induction stabilizes microtubules and promotes axon regeneration after spinal cord injury. Proc Natl Acad Sci U S A 113:11324-11329

Heras-Sandoval D, Perez-Rojas JM, Hernandez-Damian J, Pedraza-Chaverri J (2014) The role of PI3K/AKT/mTOR pathway in the modulation of autophagy and the clearance of protein aggregates in neurodegeneration. Cell Signal 26:2694-2701

Holmes D (2017) Spinal-cord injury: spurring regrowth. Nature 552:S49

Kanno H, Ozawa H, Sekiguchi A, Yamaya S, Itoi E (2011) Induction of autophagy and autophagic cell death in damaged neural tissue after acute spinal cord injury in mice. Spine (Phila Pa 1976) 36:E1427-1434

Koch JC, Knoferle J, Tonges L, Ostendorf T, Bahr M, Lingor P (2010) Acute axonal degeneration in vivo is attenuated by inhibition of autophagy in a calcium-dependent manner. Autophagy 6:658-659

Koh SH, Lo EH (2015) The role of the PI3K pathway in the regeneration of the damaged brain by neural stem cells after cerebral infarction. J Clin Neurol 11:297-304

Li X, Wu C, Chen N, Gu H, Yen A, Cao L, Wang E, Wang L (2016a) PI3K/Akt/mTOR signaling pathway and targeted therapy for glioblastoma. Oncotarget 7:33440-33450

Li Z, Yang Z, Passaniti A, Lapidus RG, Liu X, Cullen KJ, Dan HC (2016b) A positive feedback loop involving EGFR/ Akt/mTORC1 and IKK/NF-kB regulates head and neck squamous cell carcinoma proliferation. Oncotarget 7:31892-31906

Lin CJ, Chen TH, Yang LY, Shih CM (2014) Resveratrol protects astrocytes against traumatic brain injury through inhibiting apoptotic and autophagic cell death. Cell Death Dis 5:e1147

Lopez-Verrilli MA, Court FA (2012) Transfer of vesicles from schwann cells to axons: a novel mechanism of communication in the peripheral nervous system. Front Physiol 3:205

Lopez-Verrilli MA, Picou F, Court FA (2013) Schwann cellderived exosomes enhance axonal regeneration in the peripheral nervous system. Glia 61:1795-1806

McDonald JW, Sadowsky C (2002) Spinal-cord injury. Lancet 359:417-425

Mothe AJ, Tator CH (2012) Advances in stem cell therapy for spinal cord injury. J Clin Invest 122:3824-3834

MushtaqueShahjahan M (2015) Reemergence of chloroquine (CQ) analogs as multi-targeting antimalarial agents: a review. Eur J Med Chem 90:280-295

Qu Y, Franchi L, Nunez G, Dubyak GR (2007) Nonclassical IL1 beta secretion stimulated by $\mathrm{P} 2 \mathrm{X} 7$ receptors is dependent on inflammasome activation and correlated with exosome release in murine macrophages. J Immunol 179:1913-1925

Ramer LM, Ramer MS, Bradbury EJ (2014) Restoring function after spinal cord injury: towards clinical translation of experimental strategies. Lancet Neurol 13:1241-1256

Ronellenfitsch MW, Zeiner PS, Mittelbronn M, Urban H, Pietsch T, Reuter D, Senft C, Steinbach JP, Westphal M, 
Harter PN (2018) Akt and mTORC1 signaling as predictive biomarkers for the EGFR antibody nimotuzumab in glioblastoma. Acta Neuropathol Commun 6:81

Simpson RJ, Jensen SS, Lim JW (2008) Proteomic profiling of exosomes: current perspectives. Proteomics 8:4083-4099

Song M, Wang Y, Shang ZF, Liu XD, Xie DF, Wang Q, Guan H, Zhou PK (2016) Bystander autophagy mediated by radiation-induced exosomal miR-7-5p in non-targeted human bronchial epithelial cells. Sci Rep 6:30165

Sun G, Li G, Li D, Huang W, Zhang R, Zhang H, Duan Y, Wang B (2018) hucMSC derived exosomes promote functional recovery in spinal cord injury mice via attenuating inflammation. Mater Sci Eng C Mater Biol Appl 89:194-204

Thery C, Zitvogel L, Amigorena S (2002) Exosomes: composition, biogenesis and function. Nat Rev Immunol 2:569-579

Thery C, Witwer KW, Aikawa E, Alcaraz MJ, Anderson JD, Andriantsitohaina R, Antoniou A, Arab T, Archer F, AtkinSmith GK, Ayre DC, Bach JM, Bachurski D, Baharvand H, Balaj L, Baldacchino S, Bauer NN, Baxter AA, Bebawy M, Beckham C, Bedina Zavec A, Benmoussa A, Berardi AC, Bergese P, Bielska E, Blenkiron C, Bobis-Wozowicz S, Boilard E, Boireau W, Bongiovanni A, Borras FE, Bosch S, Boulanger CM, Breakefield X, Breglio AM, Brennan MA, Brigstock DR, Brisson A, Broekman ML, Bromberg JF, Bryl-Gorecka P, Buch S, Buck AH, Burger D, Busatto S, Buschmann D, Bussolati B, Buzas EI, Byrd JB, Camussi G, Carter DR, Caruso S, Chamley LW, Chang YT, Chen C, Chen S, Cheng L, Chin AR, Clayton A, Clerici SP, Cocks A, Cocucci E, Coffey RJ, Cordeiro-da-Silva A, Couch Y, Coumans FA, Coyle B, Crescitelli R, Criado MF, D'SouzaSchorey C, Das S, Datta Chaudhuri A, de Candia P, De Santana EF, De Wever O, Del Portillo HA, Demaret T, Deville S, Devitt A, Dhondt B, Di Vizio D, Dieterich LC, Dolo V, Dominguez Rubio AP, Dominici M, Dourado MR, Driedonks TA, Duarte FV, Duncan HM, Eichenberger RM, Ekstrom K, El Andaloussi S, Elie-Caille C, Erdbrugger U, Falcon-Perez JM, Fatima F, Fish, JE, Flores-Bellver, M, Forsonits A, Frelet-Barrand A, Fricke F, Fuhrmann G, Gabrielsson S, Gamez-Valero A, Gardiner C, Gartner K, Gaudin R, Gho YS, Giebel B, Gilbert C, Gimona M, Giusti I, Goberdhan DC, Gorgens A, Gorski SM, Greening DW, Gross JC, Gualerzi A, Gupta GN, Gustafson D, Handberg A, Haraszti RA, Harrison P, Hegyesi H, Hendrix A, Hill AF, Hochberg FH, Hoffmann KF, Holder B, Holthofer H, Hosseinkhani B, Hu G, Huang Y, Huber V, Hunt S, Ibrahim AG, Ikezu T, Inal JM, Isin M, Ivanova A, Jackson HK, Jacobsen S, Jay SM, Jayachandran M, Jenster G, Jiang L, Johnson SM, Jones JC, Jong A, Jovanovic-Talisman T, Jung S, Kalluri R, Kano SI, Kaur S, Kawamura Y, Keller ET, Khamari D, Khomyakova E, Khvorova A, Kierulf P, Kim KP, Kislinger T, Klingeborn M, Klinke DJ, 2nd, Kornek M, Kosanovic MM, Kovacs AF, Kramer-Albers EM, Krasemann S, Krause M, Kurochkin IV, Kusuma GD, Kuypers S, Laitinen S, Langevin SM, Languino LR, Lannigan J, Lasser C, Laurent LC, Lavieu G, Lazaro-Ibanez E, Le Lay S, Lee MS, Lee YXF, Lemos DS, Lenassi M, Leszczynska A, Li IT, Liao K, Libregts SF, Ligeti E, Lim R, Lim SK, Line A, Linnemannstons K, Llorente A, Lombard CA, Lorenowicz MJ, Lorincz AM, Lotvall J,
Lovett J, Lowry MC, Loyer X, Lu Q, Lukomska B, Lunavat TR, Maas SL, Malhi H, Marcilla A, Mariani J, Mariscal J, Martens-Uzunova ES, Martin-Jaular L, Martinez MC, Martins VR, Mathieu M, Mathivanan S, Maugeri M, McGinnis LK, McVey MJ, Meckes DG Jr, Meehan KL, Mertens I, Minciacchi VR, Moller A, Moller Jorgensen M, Morales-Kastresana A, Morhayim J, Mullier F, Muraca M, Musante L, Mussack V, Muth DC, Myburgh KH, Najrana T, Nawaz M, Nazarenko I, Nejsum P, Neri C, Neri T, Nieuwland R, Nimrichter L, Nolan JP, Nolte-'t Hoen EN, Noren Hooten N, O'Driscoll L, O'Grady T, O'Loghlen A, Ochiya T, Olivier M, Ortiz A, Ortiz LA, Osteikoetxea X, Ostergaard O, Ostrowski M, Park J, Pegtel DM, Peinado H, Perut F, Pfaffl MW, Phinney DG, Pieters BC, Pink RC, Pisetsky DS, Pogge von Strandmann E, Polakovicova I, Poon IK, Powell BH, Prada I, Pulliam L, Quesenberry P, Radeghieri A, Raffai RL, Raimondo S, Rak J, Ramirez MI, Raposo G, Rayyan MS, Regev-Rudzki N, Ricklefs FL, Robbins PD, Roberts DD, Rodrigues SC, Rohde E, Rome S, Rouschop KM, Rughetti A, Russell AE, Saa P, Sahoo S, Salas-Huenuleo E, Sanchez C, Saugstad JA, Saul MJ, Schiffelers RM, Schneider R, Schoyen TH, Scott A, Shahaj E, Sharma S, Shatnyeva O, Shekari F, Shelke GV, Shetty AK, Shiba K, Siljander PR, Silva AM, Skowronek A, Snyder OL, 2nd, Soares RP, Sodar BW, Soekmadji C, Sotillo J, Stahl PD, Stoorvogel W, Stott SL, Strasser EF, Swift S, Tahara H, Tewari M, Timms K, Tiwari S, Tixeira R, Tkach M, Toh WS, Tomasini R, Torrecilhas AC, Tosar JP, Toxavidis V, Urbanelli L, Vader P, van Balkom BW, van der Grein SG, Van Deun J, van Herwijnen MJ, Van Keuren-Jensen K, van Niel G, van Royen ME, van Wijnen AJ, Vasconcelos MH, Vechetti IJ Jr, Veit TD, Vella LJ, Velot E, Verweij FJ, Vestad B, Vinas JL, Visnovitz T, Vukman KV, Wahlgren J, Watson DC, Wauben MH, Weaver A, Webber JP, Weber V, Wehman AM, Weiss DJ, Welsh JA, Wendt S, Wheelock AM, Wiener Z, Witte L, Wolfram J, Xagorari A, Xander P, Xu J, Yan X, Yanez-Mo M, Yin H, Yuana Y, Zappulli V, Zarubova J, Zekas V, Zhang JY, Zhao Z, Zheng L, Zheutlin AR, Zickler AM, Zimmermann P, Zivkovic AM, Zocco D, Zuba-Surma EK (2018) Minimal information for studies of extracellular vesicles: a position statement of the International Society for Extracellular Vesicles and update of the MISEV2014 guidelines. J Extracell Vesicles 7:1535750

Thuret S, Moon LD, Gage FH (2006) Therapeutic interventions after spinal cord injury. Nat Rev Neurosci 7:628-643

Treda C, Popeda M, Ksiazkiewicz M, Grzela DP, Walczak MP, Banaszczyk M, Peciak J, Stoczynska-Fidelus E, Rieske P (2016) EGFR activation leads to cell death independent of $\mathrm{PI} 3 \mathrm{~K} / \mathrm{AKT} / \mathrm{mTOR}$ in an AD293 cell line. PLoS ONE 11:e0155230

Viscomi MT, D’Amelio M, Cavallucci V, Latini L, Bisicchia E, Nazio F, Fanelli F, Maccarrone M, Moreno S, Cecconi F, Molinari M (2012) Stimulation of autophagy by rapamycin protects neurons from remote degeneration after acute focal brain damage. Autophagy 8:222-235

Webber C, Zochodne D (2010) The nerve regenerative microenvironment: early behavior and partnership of axons and Schwann cells. Exp Neurol 223:51-59

Wei X, Luo L, Chen J (2019) Roles of mTOR signaling in tissue regeneration. Cells 8:1075 
Yang Y, Coleman M, Zhang L, Zheng X, Yue Z (2013) Autophagy in axonal and dendritic degeneration. Trends Neurosci 36:418-428

Yang B, Chen Y, Shi J (2019) Exosome biochemistry and advanced nanotechnology for next-generation theranostic platforms. Adv Mater 31:e1802896

Yu D, Li M, Ni B, Kong J, Zhang Z (2013) Induction of neuronal mitophagy in acute spinal cord injury in rats. Neurotox Res 24:512-522

Zhang F, Ma H, Wang ZL, Li WH, Liu H, Zhao YX (2020) The $\mathrm{PI} 3 \mathrm{~K} / \mathrm{AKT} / \mathrm{mTOR}$ pathway regulates autophagy to induce apoptosis of alveolar epithelial cells in chronic obstructive pulmonary disease caused by PM2.5 particulate matter. J Int Med Res 48:300060520927919

Zhou K, Sansur CA, Xu H, Jia X (2017) The temporal pattern, flux, and function of autophagy in spinal cord injury. Int $\mathrm{J}$ Mol Sci 18:466

Publisher's Note Springer Nature remains neutral with regard to jurisdictional claims in published maps and institutional affiliations. 